Canadian Journal of Plant Science Revue canadienne de phytotechnie

\title{
Effects of Pinching Treatment on Harvest Term and Plant Growth in Processing Tomato
}

\begin{tabular}{|r|l|}
\hline Journal: & Canadian Journal of Plant Science \\
\hline Manuscript ID & CJPS-2016-0127.R1 \\
\hline Manuscript Type: & Article \\
\hline Date Submitted by the Author: & 28-Jun-2016 \\
\hline Complete List of Authors: & $\begin{array}{l}\text { Ohta, Katsumi; Shimane University, } \\
\text { Ikeda, Daisuke; Shimane University }\end{array}$ \\
\hline Keywords: & Tomato \\
\hline
\end{tabular}


1

2

3

4

5

6

7

8

9

\section{3}

Effects of Pinching Treatment on Harvest Term and Plant Growth in Processing

\section{Tomato}

Katsumi Ohta, and Daisuke Ikeda

(1)

(1)

10

11

(1)

(3)

7 Received . Accepted .

8

K. Ohta and D. Ikeda. Department of Agriculture and Forest Sciences, Shimane University, Matsue, Shimane 690-8504, Japan.

Corresponding author: K. Ohta (email: ohta@life.shimane-u.ac.jp).

Abbreviations: DAT, days after transplanting; DW, dry weight; SSC, soluble solid contents; $\mathrm{CV}$, coefficient of variation. ${ }^{66}$ 


\begin{abstract}
The effects of pinching treatments carried out at the 3- and 6-true-leaf stages on harvest term and plant growth in processing tomato 'Shuho' (Solanum lycopersicum L.) were examined. Weekly yields in the 3- and 6-true-leaf pinching treatments were increased compared to those in the untreated control at 1 and 2 weeks after the start of harvest, respectively. There were no differences among all treatments in yield, fruit weight, fruit number, or marketable fruit ratio. However, the fruit set ratio in the 3-true-leaf pinching treatment was increased more than those in the other treatments. The flowering periods in the pinching-treatment groups were shorter than those of the control. The number of flowers per lateral shoot in the pinching-treatment groups was greater than that in the control. DW in the lateral shoots in the 3-true-leaf pinching treatment was significantly greater than that in other treatment groups. The distribution of nitrogen and calcium in the lateral shoots in the 3-true-leaf pinching treatment was increased compared to those in other treatment groups. This result suggests that shortening of harvest term and increase of initial fruit yield in the 3-true-leaf pinching treatment would be more efficient practices in processing tomato cultivation.
\end{abstract}

Keywords: lateral shoot; apical dominance; mineral nutrient; number of flowers; Solanum lycopersicum. 


\section{Introduction}

Indeterminate tomato cultivars are usually cultivated for the commercial fresh produce market. All of the lateral shoots of these cultivars except those generated from the first node below the terminal flower truss are removed periodically. The growth of lateral shoots in the indeterminate cultivars can be extended by pinching (Brenner et al. 1987; Cline 1996; Tucker $1977 \mathrm{a}, \mathrm{b})$. In some tomato cultivars, the numbers and weights of fruits that grew on double-stemmed plants created by topping treatments were greater than those that grew on single-stemmed plants (Ece and Darakci 2007; Maboko et al. 2011; Xu et al. 2003). In addition, pinching at the seedling stage can increase the number of double clusters and flowers on lateral shoots of cherry tomatoes (Kozai 2013; Motoki et al. 1996).

Determinate tomatoes are cultivated mainly for processing and cooking. Their lateral shoots are generally allowed to grow and are not removed (Fukui et al. 1990; Ito 1992; Yanokuchi 1997). However, lack of fruit set on the first flower truss due to low or high temperatures or rainfall or due to pinching at the seedling stage can affect the lateral shoot lengths and flowering periods of processing tomato plants.

Pinching, which has also been referred to as topping or apical pruning, is often performed to increase initial tomato yield, but there are differences among cultivars as to the effects of pinching (Knott 1927; Sayre 1948). In addition, when the stem is pinched above 0 to 3 true leaves, the lengths of the lateral shoots at each node do not substantially differ, whereas if the stem is pinched above 4 to 6 true leaves, the lengths of the lateral shoots can differ greatly (Ito 1992). Because a relationship among the lengths of lateral shoots, the number of lateral shoots per primary lateral shoot, and the number of flowers is expected in processing tomatoes, growth of the lateral shoot would be influenced by the uptake and distribution of mineral nutrients in each organ. Because pinching can enhance the uniformity of fruit maturity, Ito (1992) proposed that in processing tomato cropping, pinching could 
shorten the harvest term while also, due to this shorter flowering period, leading to harvest periods with more than $80 \%$ total fruit yield. However, there has been little further information about the effects of pinching treatments on the harvest term, yield, growth of lateral shoots, flowering, and number of flowers in processing tomato cultivars, and there has been little research on the relationship between the growth of lateral shoots and the uptake of mineral nutrients. The purpose of the present study was thus to clarify the effects of pinching treatments on harvest term, plant growth, and the uptake of mineral nutrients in a processing tomato cultivar.

\section{Materials and Methods}

Experimental site, plant materials, growing conditions, and treatments. The processing tomato 'Shuho' (Solanum lycopersicum L.) (Nagano Chushin Agricultural Institute Experimental Station, Shiojiri, Japan) was used for these experiments. Seeds were sown in yellowish pumice (diameter $2-5 \mathrm{~mm})$ in plastic containers $(34.5 \times 27.0 \times 7.5 \mathrm{~cm})$ on 2014 Apr. 2. All containers were placed in a greenhouse at Shimane University, Matsue, Japan. One plant was potted in $12 \mathrm{~cm}$ diam. $\times 10 \mathrm{~cm}$ deep $(0.6 \mathrm{~L})$ black plastic pots in potting medium containing 50\% sandy loam and 50\% bark compost on Apr. 18 .

After the third and sixth true leaves had expanded, the plants were pinched at the stem above the third and sixth true leaves on May 9 and 16, respectively. No pinching treatments were performed in the untreated control.

When the sixth true leaf of the control plants had fully expanded, the tomato plants were transplanted into the experimental field with the soil surface covered with black $0.02-\mathrm{mm}$ polyethylene film and with the addition of $3.5 \mathrm{~kg} \mathrm{a}^{-1}$ of 16-3.9-8.3 NPK solid fertilizer before mulching on May 19 at Yatsuka-cho, Matsue, Japan (lat. $35^{\circ} 29^{\prime} \mathrm{N}$, long. $133^{\circ} 10^{\prime} \mathrm{E}, 24$ $\mathrm{m}$ a.s.1.). Soil moisture was maintained between $\mathrm{pF} 1.8$ and 2.5 using furrow irrigation twice 
per week and tensiometers (DM-8, Takemura Electrical Factory Co. Ltd., Tokyo). The experimental plot was $28 \mathrm{~m}^{2}$, and planted in a single row $1.6 \mathrm{~m}$ wide, with $80-\mathrm{cm}$ spacing between rows, with $45-\mathrm{cm}$ spacing between plants, and a planting density of 1.39 plants $\mathrm{m}^{-2}$. Experiments were arranged in a randomized complete block design with three replicates. Eight plants were used for each pinching treatment. Six plants per treatment were used for the measurement of the lateral shoot growth, flowering, and yields, and the remaining plants were used for the analysis of mineral nutrient contents.

The average air temperature in the field from transplanting to the end of harvest was $28.3^{\circ} \mathrm{C}$, and the maximum and minimum temperatures were $36.0^{\circ} \mathrm{C}$ and $19.4^{\circ} \mathrm{C}$, respectively. No insecticides and fungicides were used.

Measurements. At 18 and 59 days after transplanting (DAT), the lengths of the lateral shoots generated from each node were measured. The first flowering dates of the main stem and the first truss of each lateral shoot, and the numbers of flowers and secondary or other lateral shoots were recorded. Mature red fruits were harvested twice per week, and the fruit number, fruit weight, and the number of marketable fruits (i.e. except for blossom-end rot, malformation, sunburn, and cracked fruits) were recorded. The soluble solids content (SSC) of 20 marketable fruits that were harvested during the second and third weeks after the start of harvest in each plot were measured using a digital refractometer (APAL-1, AS ONE Corp., Osaka, Japan).

At 18 DAT, the plants were sampled and divided into stems, leaves on the main shoot, and lateral shoots, and then washed with deionized water. Two plants were sampled from each plot, and there were three replications. After being air-dried at $80 \pm 5^{\circ} \mathrm{C}$ for $72 \mathrm{~h}$, the dried plants were ground in an electric mill to a fine powder with three replications. Total nitrogen $(\mathrm{N})$ contents were analyzed using a $\mathrm{CN}$ coder (Sumigraph NC-22F, Sumitomo Chemical Analysis Center Corp., Tokyo). After dry ashing, the phosphorus (P) contents were 
determined by vanadomolybdate absorption spectrometry, and the potassium (K), calcium (Ca), and magnesium ( $\mathrm{Mg})$ contents were determined using an atomic absorption spectrophotometer (AA-630, Shimadzu, Kyoto, Japan). The content of mineral nutrients in each plant was calculated from these data.

Statistical analysis. Data were analyzed using an analysis of variance (ANOVA) and $t$-test in SPSS ver. 19.0.0 (SPSS, Chicago, IL) and the differences among means were determined using by Tukey's test at $P<0.05$.

\section{Results and Discussion}

Figure 1 shows the weekly marketable fruit yield after the start of harvest. The weekly yield in the 3-true-leaf pinching-treatment group at $1 \mathrm{wk}$ after the start of the harvest was higher, at $1.0 \mathrm{~kg} \mathrm{plant}^{-1}$, than the weekly yield in the controls at $0.7 \mathrm{~kg} \mathrm{plant}^{-1}$. The weekly yield in the 6-true-leaf pinching-treatment group at $2 \mathrm{wk}$ after the start of the harvest was also higher, at $1.1 \mathrm{~kg}$ plant ${ }^{-1}$, than that in the controls at $0.7 \mathrm{~kg} \mathrm{plant}^{-1}$. The harvest term in the pinching treatments was shortened until $3 \mathrm{wk}$ after the start of harvest compared to that in the control until $4 \mathrm{wk}$ after the start of harvest. These findings are in agreement with those of earlier studies (Ito et al. 1980; Knott 1927; Sayre 1948). In particular, the potential for both shortening the harvest term and increasing the early yield was realized with the 3-true-leaf pinching treatment. Previous studies have suggested that such shortening of the harvest term would save labor and permit mechanical harvesting (Arima and Nakamura 1969; Arima et al. 1973; Stephenson 1964; Stout and Ries 1960).

Table 1 shows the fruit yield per plant, the weight and number of harvested fruits, the fruit set ratio, the marketable fruits ratio and the $\mathrm{SSC}$. The fruit set ratio was significantly higher, at 29 to $61 \%$, in the 3-true-leaf pinching-treatment group than in the other treatment groups, but the fruit yield per plant, the weight and number of harvested fruits, the 
marketable fruits ratio, and SSC did not differ among the treatments.

Table 2 shows the number of days from sowing to first flowering and the number of days between the first and last flowering of the terminal flower truss of the main stem or lateral shoot. The first flowering in the control occurred earlier, at $8 \mathrm{~d}$, than in the pinching-treatment groups. The number of days to the first flowering of the lateral shoots did not differ between the pinching-treatment groups, but this parameter did differ between the pinching-treatment groups and the control, at $23.7 \mathrm{~d}$, due to the lack of a terminal flower truss on the main stem in the pinched plants. Although the number of days between the first and last flowering of the lateral shoots in the 3-true-leaf pinching-treatment group was significantly lower, at $13.1 \mathrm{~d}$, than that in the control, at $18.7 \mathrm{~d}$, no differences in the number of days between the first and last flowering of the terminal flower truss of each lateral shoot were observed between the 6-true-leaf pinching-treatment group and the controls.

Table 3 shows the number of flowers per plant, the number of flowers per lateral shoot and the number of secondary and other lateral shoots per primary lateral shoot. The number of flowers per plant in the 6-true-leaf pinching-treatment group was significantly higher, at 239.6 flowers, compared to that of the control at 198.5 flowers. However, the number of flowers per plant was significantly lower, at 158.3 flowers, in the 3 -true-leaf pinching-treatment group. The number of flowered lateral shoots per plant in the 3-true-leaf pinching-treatment group was significantly lower, at 4.8, than those in the other treatment groups. The numbers of flowers per lateral shoot in both pinching-treatment groups were significantly higher, at 33.5 and 26.8 flowers, respectively, compared to the control at 21.6 flowers. Although the numbers of flowers per whole plant in the control and 6-true-leaf pinching-treatment groups were greater than those in the 3-true-leaf pinching-treatment group, the numbers of harvested fruits did not differ among the treatments. We propose that the numbers of dropped flowers in the control and 6-true-leaf pinching-treatment groups 
were greater than in the 3-true-leaf pinching-treatment group because of the excessive number of flowers per plant.

Although the number of flowers per primary lateral shoot was similar in all treatments, the flower numbers per secondary and other lateral shoots in both pinching-treatment groups were significantly higher than in the control. Arima et al. (1997) reported that the number of flowers on longer lateral shoots could be increased in processing tomatoes. In eggplants, there are more flowers on pinched plants than on unpinched plants, which could be due to the increased number of lateral shoots on the former (Ishida 1983). Therefore, the increases in the numbers of flowers and secondary and other lateral shoots on plants in the pinching-treatment groups compared to the control in the present study were likely due to the release of apical dominance in tomato plants, which results in the growth of lateral shoots, as described previously (Brenner et al. 1987; Cline 1996; Tucker 1977a, b).

From these results, because the flowering period in the 3-true-leaf pinching-treatment group was shorter than those in the other treatment groups (Table 2), the decreased fruit set ratio that can occur during periods of high air temperatures might have been avoided by using this technique, as suggested previously (Iwahori et al. 1963). Therefore, although there were significantly fewer flowers in the 3-true-leaf pinching-treatment group (Table 3), the total yield did not differ compared to the other treatments because the fruit set ratio in the 3-true-leaf pinching-treatment group was higher than in the other treatment groups (Table 1).

Figure 2 shows the lateral shoot lengths at 18 and 59 DAT. At 18 DAT, the lateral shoots of all nodes in the 3-true-leaf pinching-treatment group had grown significantly longer than those in the controls. Although the lateral shoot lengths generated from the two cotyledonary and first true leaf nodes in the 6-true-leaf pinching-treatment group did not differ compared to those in the controls, the lateral shoots generated from the second to sixth true leaf nodes had grown significantly longer, to a maximum of $21.1 \mathrm{~cm}$, than those in the controls. At 59 
DAT, the lateral shoot lengths in the pinching-treatment groups showed the same tendencies as seen at 18 DAT. The mean lateral shoot lengths in the pinching-treatment groups was significantly longer, at 44.6 and $35.5 \mathrm{~cm}$, than those in the controls. In a study conducted with the processing tomato 'Wase Daruma', the differences in lateral shoot lengths among plants that underwent pinching treatment at 0 to 3 true leaves were smaller than in plants that underwent pinching treatment at 4 to 6 true leaves (Ito 1992). In the present experiment, almost the same result was obtained in regard to the lateral shoot lengths in the different pinching-treatment groups. Kaizuka and Suzuki (2004) reported that in 'Beni Kodama' and 'Beni Kodama V' watermelons, the shoot lengths of 3-scaffold shoots created by pinching were longer than those of 6-scaffold shoots because of reduced nutrient competition among the remaining shoots. This might also be the reason that the mean lateral shoot lengths in the present 3-true-leaf pinching-treatment group were more uniform than those in the 6-true-leaf pinching-treatment group at 59 DAT (Fig. 2). Perhaps the emergence period of axillary buds was shorter and the competition for absorbed mineral nutrients was reduced in the plants that underwent the 3-true-leaf pinching treatment.

Figure 3 shows DW of the plants in this study. Although total DW did not differ among all treatment groups, DW in the stem in the 3-true-leaf pinching-treatment group was significantly less, at $0.74 \mathrm{~g} \mathrm{plant}^{-1}$, than those in the other treatment groups, and DW of leaves in the 3-true-leaf pinching-treatment group was significantly less than that in the control. DW in the lateral shoot in the 3-true-leaf pinching-treatment group was highest among all treatment groups by a significant degree.

Table 4 shows the content and distribution of $\mathrm{N}, \mathrm{P}, \mathrm{K}, \mathrm{Ca}$, and $\mathrm{Mg}$ in the plants. The $\mathrm{P}$ and $\mathrm{K}$ content in the stems of plants in the 3-true-leaf pinching-treatment group was significantly less than that in the control, but the uptake of these nutrients in the 6-true-leaf pinching-treatment group did not differ from that in the control. In the leaves, there were no 
differences in the content of mineral nutrients among the different treatments. In the lateral shoots, the $\mathrm{N}, \mathrm{P}, \mathrm{K}, \mathrm{Mg}$, and $\mathrm{Ca}$ content in the 3-true-leaf pinching-treatment group were significantly greater, $56.8,7.2,31.8,29.1$, and $6.3 \mathrm{~g}$ plant $^{-1}$, respectively, than those in the control. In the lateral shoots, the $\mathrm{N}, \mathrm{K}$, and $\mathrm{Ca}$ content in the 6-true-leaf pinching-treatment group was significantly greater than that of the control. The total content of $\mathrm{N}$ and $\mathrm{Ca}$ in the 3-true-leaf pinching-treatment group was increased, at 85.2 and $90.5 \mathrm{~g} \mathrm{plant}^{-1}$, respectively, compared to that of the control. The $\mathrm{P}$ and $\mathrm{K}$ distributions to the stem in the 3-true-leaf pinching-treatment group were lower than those in the control, whereas the distribution of all five measured elements to the lateral shoots was higher in this treatment group than in the control. Therefore, the growth of lateral shoots, especially in the 3-true-leaf pinching-treatment group, was greater than that in the control, which was likely due to the increased uptake of mineral nutrients - especially $\mathrm{N}$ and $\mathrm{Ca}$ - and because the distribution of mineral nutrients was changed by pinching treatment.

Pinching releases apical dominance, and removes a metabolic sink in plants (Cline 1991). This results in decreased auxin production in the apical bud and increased nutrient distribution into and growth of the lateral shoots (Hillman 1984; Nakamura 1967). The levels and distribution of $\mathrm{N}, \mathrm{P}$, and $\mathrm{K}$ were increased in the lateral shoots of bean plants in relation to apical dominance (Phillips 1975). Calcium, a structural component of the cell wall and membranes, is needed for tomato plant growth at early growth stages (Halbrooks and Wilcox 1980), and its uptake under high-growth conditions was increased in tomato shoots (Nakano et al. 2006; Hawkesford et al. 2012). Fukui et al. (1990) also reported that increased flower numbers were due to the relatively greater availability of photosynthetic products in tomato cultivars with large leaf areas. The number of flowers in tomato plants is also increased by higher contents of $\mathrm{N}$ and $\mathrm{P}$ (Saito et al. 1963). Decoteau (1990) reported that topping enhanced axillary leaf development in processing tomato cultivars. Thus, pinching 
treatments likely increase the photosynthetic products and mineral nutrient uptake by increasing the lateral shoot leaf areas, and also likely lead to increased numbers of flowers.

In conclusion, the shortening of harvest term and increase of initial fruit yield in the 3-true-leaf pinching treatment is due to enhanced lateral shoot growth and shortening of the flowering periods. Therefore, this study suggests that the present treatment could permit machine harvesting and save costs during harvest. The results of these experiments indicate that further studies should be undertaken to elucidate the relationships among lateral shoot growth, the number of flowers, second and further lateral shoots, physiological factors such as the nutritional status of lateral shoots after flower bud differentiation and the distribution of photosynthetic products in processing tomato plants.

\section{Acknowledgements}

We are grateful to Professor Hiroyuki Itamura for thoughtful comments and support over the course of this study.

\section{References}

Arima, H. and Nakamura, H. 1969. Studies on the laborsaving culture of processing tomato. J. Fac. Agric. Shinshu Univ. 6: 83-99 [in Japanese, English abstract].

Arima, H., Tsuchiya, T., Fukaya, K. and Nakamura, R. 1973. Studies on the laborsaving culture of processing tomato. On the trial fruits conveyer and mechanical harvester. J. Fac. Agric. Shinshu Univ. 10: 75-114 [in Japanese, English abstract].

Arima, H., Kobayashi, T. and Murata H. 1997. Growing phase of the flowering, fruiting and ripening of processing tomato. J. Fac. Agric. Shinshu Univ. 8: 11-23 [in Japanese].

Brenner, M.L., Wolly, D.J., Sjut, V. and Salerno, D. 1987. Analysis of apical dominance in relation to IAA transport. HortScience 22: 833-835. 
Cline, M.G. 1991. Apical Dominance. The Botanical Review 57: 318-358. doi: 10.1007/BF02858771.

Cline, M.G. 1996. Exogenous auxin effects on lateral bud outgrowth in decapitated shoots. Ann. Bot. 78: 255-266. doi: 10.1006/anbo.1996.0119.

Decoteau, D.R. 1990. Tomato leaf development and distribution as influenced by leaf removal and decapitation. HortScience 25: 681-684.

Ece, A. and Darakci, N. 2007. Determination of relationships between number of stem and yield of tomato (Lycopersicon lycopersicum L.). Asian J. Plant Sci. 6: 802-808.

Fukui, H., Iguch, H. and Nakamura, M. 1990. Characteristics of determinate type tomatoes. Res. Bull. Fac. Agric. Gifu Univ. 55: 125-135 [in Japanese, English abstract].

Halbrooks, M.C. and Wilcox, G.E. 1980. Tomato plant development and elemental accumulation. J. Am. Soc. Hortic. Sci. 105: 826-828.

Hawkesford, M., Horst, W., Kichey, T., Lambers, H., Schjoerring, J., Møller, I.S. and White, P. 2012. Part I. Nutritional Physiology. 6. Functions of Macronutrients. Pages 135-190 in P. Marschner, ed. Marschner's Mineral Nutrition of Higher Plants, 3rd ed. Academic press, London, UK. doi: 10.1016/B978-0-12-384905-2.00006-6.

Hillman, J.R. 1984. Apical dominance. Pages 127-148 in M.B. Willkins, ed. Advanced Plant Physiology. Pitman, London, UK.

Ishida, K. 1983. Effect of pinching at different stages of growth on flowering and fruit yield of eggplants. Sci. Rep. Fac. Agric. Kobe Univ. 15: 235-240 [in Japanese, English abstract].

Ito, K., Kamimura, S. and Kanno, K. 1980. Effect of topping at seedling stage on the flowering convergence in tomato (Preliminary study). Abstr. Tohoku Branch Jpn. Soc. Hortic. Sci. 55: 59-60 [in Japanese]. 
Ito, K. 1992. A study on the establishment of breeding technology for labor-saving harvest facing breeding in the processing tomatoes. Ph.D. thesis, Tohoku University, Sendai, Japan, 275 pp [in Japanese].

Iwahori, S., Sakiyama, R. and Takahashi, K. 1963. High temperature injuries in tomatoes. I. Effects of different temperatures on fruit setting and of seedlings treated at different stages of growth. J. Jpn. Soc. Hortic. Sci. 32: 197-204 [in Japanese, English abstract].

Kaizuka, T. and Suzuki, M. 2004. Influence of the different methods of growth and environment training of fruit in small type watermelon. Bull. Hortic. Inst. Ibaraki-Agric. Center 12: 1-7 [in Japanese, English abstract].

Knott, J.E. 1927. The effect of apical pruning of tomato seedlings on growth and early yield. Proc. Am. Soc. Hortic. Sci. 24: 21-23.

Kozai, S. 2013. Effect of pinching and leaf-thinning treatment at seedling stage on development of double cluster and the number of flowers of cherry tomato. Hortic. Res. (Jpn), 12 (Suppl. 1):101 [in Japanese].

Maboko, M.M., Du Plooy, C.P. and Chiloane, S. 2011. Effect of plant population, fruit and stem pruning on yield and quality of hydroponically grown tomato. Afr. J. Agric. Res. 6: 5144-5148. doi: 10.5897/AJAR11.1316.

Motoki, S., Ito, M., Yanokuchi, S., Okamoto, K. and Nakamura, T. 1996. Effect of topping management of cherry tomatoes on the form of flower cluster, characteristic of flowering and fruit ripening, characteristic of fruit quality and fruit yield. Bull. Nagano Chushin Agric. Exp. Sta. 13: 63-74 [in Japanese, English abstract].

Nakamura, E. 1967. Studies on the branching in Pisum sativum L. VI. Physiological and anatomical aspects of branch development. J. Jpn. Soc. Hortic. Sci. 36: 77-88 [in Japanese, English abstract]. 
Nakano, Y., Watanabe, S., Kawashima H. and Takaichi M. 2006. The effect of daily nutrient applications on yield, fruit quality, and nutrient uptake of hydroponically cultivated tomato. J. Jpn. Soc. Hortic. Sci. 75: 421-429 [in Japanese, English abstract].

Phillips, I.D.J. 1975. Nitrogen, phosphorus, and potassium distribution in relation to apical dominance in dwarf bean (Phaseolus vulgaris, c.v. Canadian Wonder). J. Exp. Bot. 19: 617-627.

Saito, T., Hatayama, T. and Ito, H. 1963. Studies on the growth and fruiting in the tomato. III. Effect of the early environment on the flowering (3) Nutrition of nitrogen, phosphorus and potassium. J. Jpn. Soc. Hortic. Sci. 32: 131-142 [in Japanese, English abstract].

Sayre, C.B. 1948. Early and total yields of tomatoes as affected by time of seedling, topping the plants, and space in the flats. Proc. Am. Soc. Hortic. Sci. 51: 367-370.

Stephenson, K.Q. 1964. Selective fruit separation for mechanical tomato harvester. Agric. Eng. 45: 250-253.

Stout, B.A. and Ries, S.K. 1960. Development of a mechanical tomato harvester. Agric. Eng. 41: $682-688$.

Tucker, D.J. 1977a. Hormonal regulation of lateral bud outgrowth in the tomato. Plant Sci. Lett. 8: 105-111.

Tucker, D. J. 1977b. Apical dominance in the 'Rogue' tomato. Ann. Bot. 41: 181-190.

$\mathrm{Xu}, \mathrm{R} ., \mathrm{Xu}, \mathrm{H}$. and Wang T. 2003. Effects of removing lower leaves and topping treatment on greenhouse tomatoes. Japanese J. Crop Sci. 72 (Suppl. 1): 264-265 [in Japanese].

Yanokuchi, Y. 1997. Basic edition. Tomato. V. Cultivation point and cultivation system. Cultivation of the processing tomatoes. Compendium of agricultural technology. Pages 607-613 Vegetables 2. in Tomato. Nobunkyo, Tokyo, Japan [in Japanese]. 


\section{$345 \quad$ Figure captions}

346

347

348

349

350

351

352

353

354

355

356

357

358

359

360

361

362

363
Fig. 1. Effect of pinching treatment on weekly marketable fruit yield in processing tomato. Different letters within each week indicate significant difference at $P<0.05$ (Tukey's test) and error bars indicate standard error $(n=6)$.

Fig. 2. Effect of pinching treatment on lateral shoot length and coefficient of variation (CV) at $18 \mathrm{~d}$ after transplanting (DAT) (a) and 59 DAT (b) in processing tomato. * and ** indicate significant difference at $P<0.05$ and $P<0.01$, respectively. Different letters within each node indicate significant difference at $P<0.05$ (Tukey's test) and error bars indicate standard error (n $=6)$.

Fig. 3. Effect of pinching treatment on the dry weight (DW) at $18 \mathrm{~d}$ after transplanting (DAT) in processing tomato. Different letters within each organ indicate significant difference at $P<$ 0.05 (Tukey's test) and error bars indicate standard error $(n=3)$. 
Table 1. Effect of pinching treatment on the fruit yield, fruit weight, number of fruits, fruit set ratio, marketable fruit ratio, and soluble solids contents $5 \quad$ (SSC) in processing tomato.

\begin{tabular}{|c|c|c|c|c|c|c|c|}
\hline Treatment & $\begin{array}{l}\text { Fruit yield } \\
\left(\text { g plant }^{-1}\right)\end{array}$ & 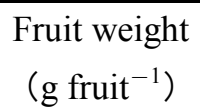 & $\begin{array}{l}\text { Number of fruits } \\
\left.\qquad \text { (g plant }^{-1}\right)\end{array}$ & $\begin{array}{l}\text { Fruit set ratio } \\
\qquad(\%)\end{array}$ & $\begin{array}{c}\text { Marketable fruit ratio } \\
\qquad(\%)\end{array}$ & $\begin{array}{l}\mathrm{SSC} \\
(\%)\end{array}$ & \\
\hline Control & $2,970 \quad a$ & $94.8 \quad a$ & $31.2 a$ & $15.8 a$ & $87.6 \quad a$ & 4.9 & $a$ \\
\hline Pinch-3 & 3,018 & $94.7 \quad a$ & $31.7 a$ & $20.4 \quad b$ & 89.6 & 5.1 & $a$ \\
\hline Pinch-6 & 2,968 & 98.3 & $30.3 a$ & 12.7 & 88.2 & 5.1 & $a$ \\
\hline
\end{tabular}

Note: Pinch-3 or 6- indicates pinching treatment with the plant left with three or six true leaves, respectively. 
Table 2. Effect of pinching treatment on the number of days from sowing to first flowering, and the number of days between the first and last flowering of the terminal flower truss in processing tomato.

\begin{tabular}{|c|c|c|c|}
\hline \multirow{2}{*}{ Treatment } & \multirow{2}{*}{$\begin{array}{c}\text { Days from sowing to } \\
\text { first flowering } \\
\text { Terminal flower truss of } \\
\text { main stem or lateral shoot }\end{array}$} & \multicolumn{2}{|c|}{ Number of days between first and last flowering } \\
\hline & & $\begin{array}{l}\text { Terminal flower truss of main } \\
\text { and/or each lateral shoot }\end{array}$ & $\begin{array}{c}\text { Terminal flower truss } \\
\text { of each lateral shoot }\end{array}$ \\
\hline Control & 57.5 & $23.7 c$ & 18.7 \\
\hline Pinch-3 & $64.5 b$ & $13.1 a$ & $13.1 a$ \\
\hline Pinch-6 & 64.6 & $18.1 \quad b$ & $18.1 b$ \\
\hline
\end{tabular}

Note: Pinch-3 or 6- indicates pinching treatment with the plant left with three or six true leaves, respectively. $a-c$ Different letters in italic type within each column indicate significant difference at $P<0.05$ (Tukey's test). 
Table 3. Effect of pinching treatment on the number of flowers, flowering lateral shoots, and secondary and other lateral shoots per primary lateral shoot

24 in processing tomato.

\begin{tabular}{|c|c|c|c|c|c|c|}
\hline Treatment & $\begin{array}{c}\text { Number of flowers } \\
\text { per whole plant }\end{array}$ & $\begin{array}{c}\text { Number of flowered } \\
\text { lateral shoots } \\
\text { per whole plant }\end{array}$ & \multicolumn{3}{|c|}{ Number of flowers per lateral shoot } & $\begin{array}{c}\text { Number of secondary and } \\
\text { higher lateral shoots } \\
\text { per primary lateral shoot }\end{array}$ \\
\hline Pinch-3 & 158.3 & $4.8 \quad a$ & 33.5 & 5.0 & 27.9 & 6.4 \\
\hline Pinch-6 & 239.6 & 9.0 & $26.8 b$ & 5.1 & 21.8 & 5.4 \\
\hline
\end{tabular}

Note: Pinch-3 or 6- indicates pinching treatment with the plant left with three or six true leaves, respectively.

$a-c$ Different letters in italic type within each column indicate significant difference at $P<0.05$ (Tukey's test). 
Table 4. Effect of pinching treatment on the content and distribution of $\mathrm{N}, \mathrm{P}, \mathrm{K}, \mathrm{Ca}$, and $\mathrm{Mg}$ at $18 \mathrm{~d}$ after transplanting (DAT) in processing tomato.

\begin{tabular}{|c|c|c|c|c|c|c|c|c|c|c|c|c|c|c|c|c|}
\hline Organ & Treatment & \multicolumn{3}{|c|}{$\mathrm{N}$} & \multicolumn{3}{|c|}{$\mathrm{P}$} & \multicolumn{3}{|c|}{$\mathrm{K}$} & \multicolumn{3}{|c|}{$\mathrm{Ca}$} & \multicolumn{3}{|c|}{$\mathrm{Mg}$} \\
\hline \multirow{2}{*}{ Stem } & Control & 7.9 & $a$ & $(13)^{z}$ & 2.9 & $b$ & $(25)$ & 16.5 & $b$ & $(31)$ & 17.8 & $a$ & (24) & 4.3 & $a$ & $(30)$ \\
\hline & Pinch-6 & 8.2 & $a$ & (11) & 2.6 & $b$ & (20) & 15.8 & $b$ & $(26)$ & 16.3 & $a$ & $(23)$ & 4.2 & $a$ & (29) \\
\hline \multirow{2}{*}{ Leaf } & Control & 26.2 & $a$ & $(42)$ & 4.2 & $a$ & (36) & 14.4 & $a$ & (27) & 40.0 & $a$ & $(55)$ & 5.9 & $a$ & (42) \\
\hline & Pinch-6 & 23.3 & $a$ & (31) & 3.6 & $a$ & (28) & 13.7 & $a$ & $(23)$ & 36.6 & $a$ & $(50)$ & 5.3 & $a$ & $(36)$ \\
\hline \multirow{3}{*}{$\begin{array}{c}\text { Lateral } \\
\text { shoot }\end{array}$} & Control & 28.2 & $a$ & $(45)$ & 4.6 & $a$ & (39) & 22.4 & $a$ & $(42)$ & 15.0 & $a$ & $(21)$ & 3.9 & $a$ & $(28)$ \\
\hline & Pinch-3 & 56.8 & $c$ & (67) & 7.2 & $b$ & (59) & 31.8 & $b$ & $(59)$ & 29.1 & $c$ & (32) & 6.3 & $b$ & (39) \\
\hline & Pinch-6 & 42.9 & $b$ & (58) & 6.7 & $b$ & $(52)$ & 30.3 & $b$ & (51) & 19.9 & $b$ & $(27)$ & 5.2 & $a b$ & $(35)$ \\
\hline \multicolumn{17}{|l|}{$P$} \\
\hline \multicolumn{2}{|c|}{ Organ (A) } & \multicolumn{3}{|l|}{$\mathrm{NS}$} & \multicolumn{3}{|l|}{ NS } & \multicolumn{3}{|l|}{ NS } & \multicolumn{3}{|l|}{$*$} & \multicolumn{3}{|l|}{ NS } \\
\hline \multicolumn{2}{|c|}{ Treatment (B) } & \multicolumn{3}{|l|}{$* *$} & \multicolumn{3}{|l|}{$* *$} & \multicolumn{3}{|l|}{$* *$} & \multicolumn{3}{|l|}{$* *$} & \multicolumn{3}{|l|}{ * } \\
\hline \multicolumn{2}{|c|}{$\mathrm{A} \times \mathrm{B}$} & \multicolumn{3}{|l|}{ NS } & \multicolumn{3}{|l|}{ NS } & $\mathrm{NS}$ & & & NS & & & NS & & \\
\hline
\end{tabular}

Note: Pinch-3 or 6- indicates pinching treatment with the plant left with three or six true leaves, respectively.

${ }^{\mathrm{z}}$ Values are the ratio of the nutrient amount in each organ to the total in each treatment.

$a-c$ Different letters within each column indicate significant difference at $P<0.05$ (Tukey's test).

*, **, NS: significant at $P<0.05$ and $P<0.01$ or not significant, respectively (ANOVA). 
Fig. 1.

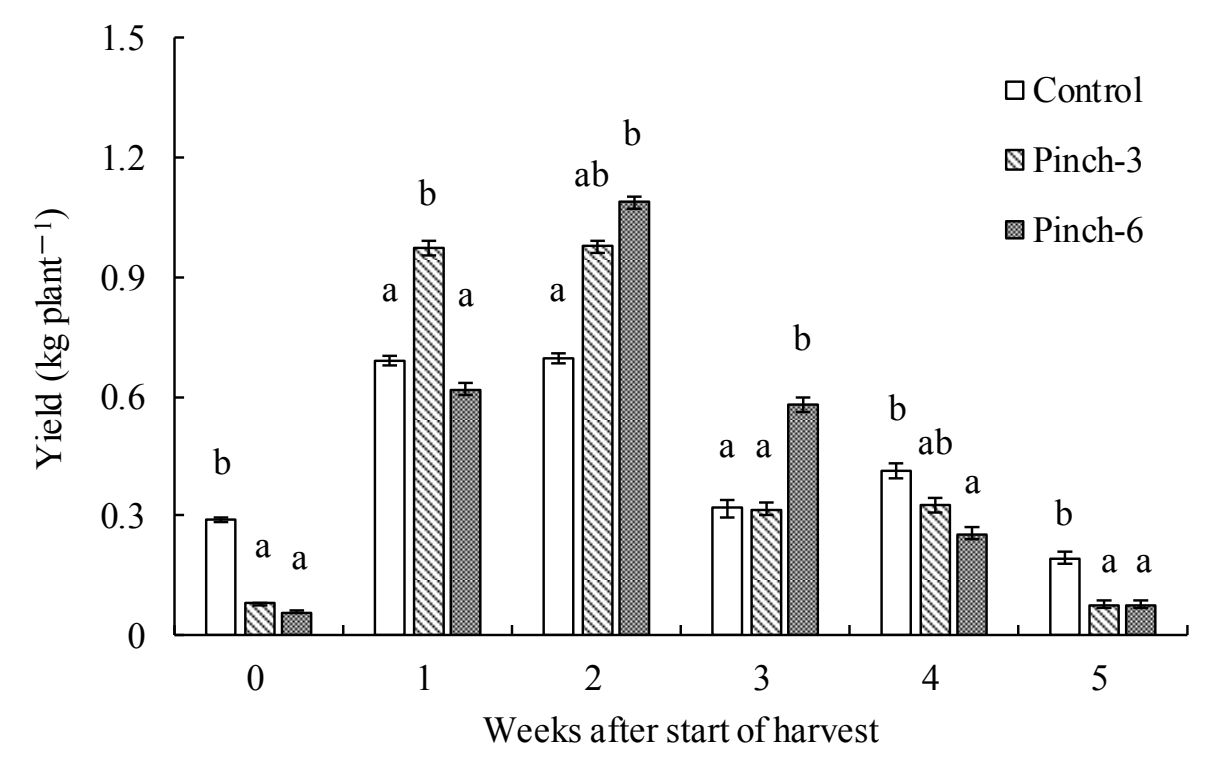


(a)

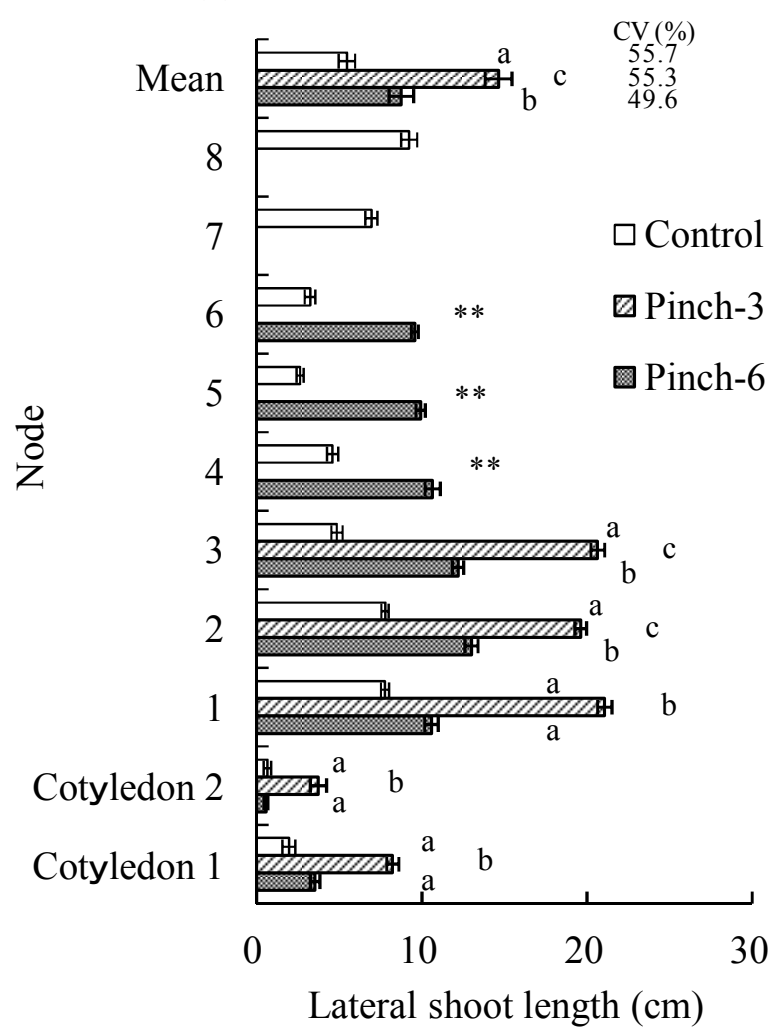

(b)

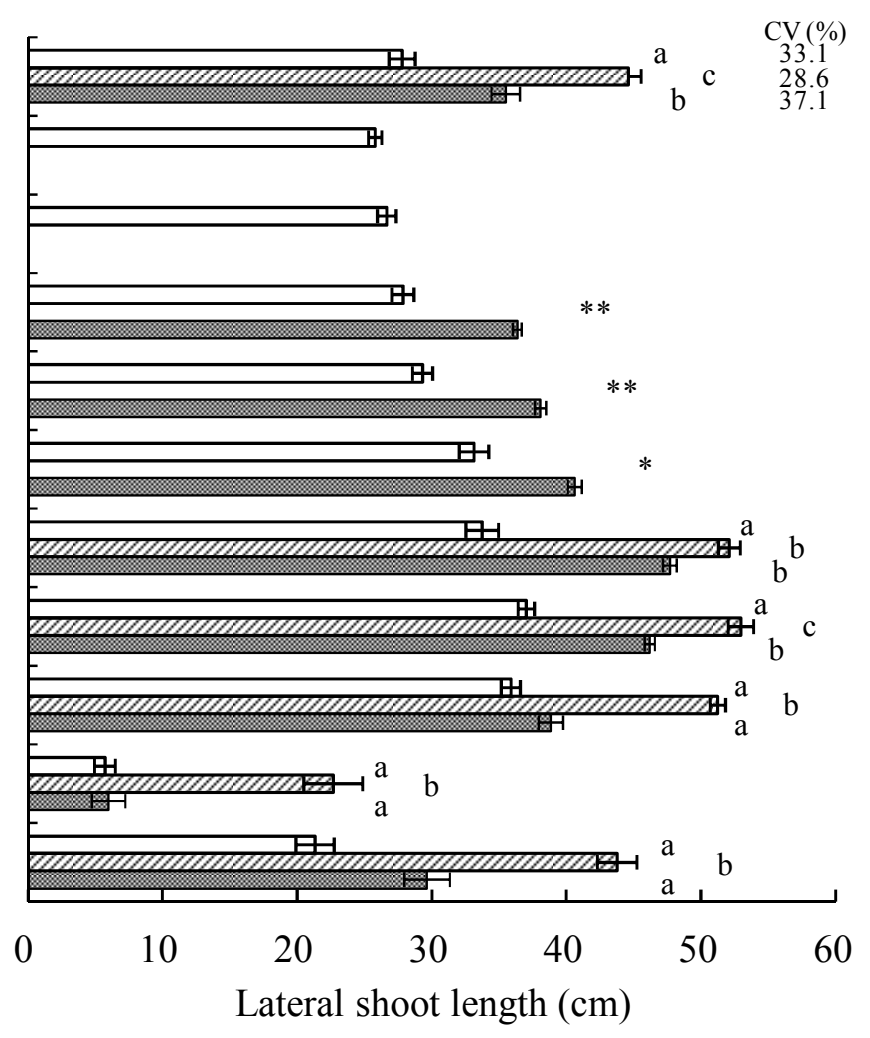


Fig. 3.

10

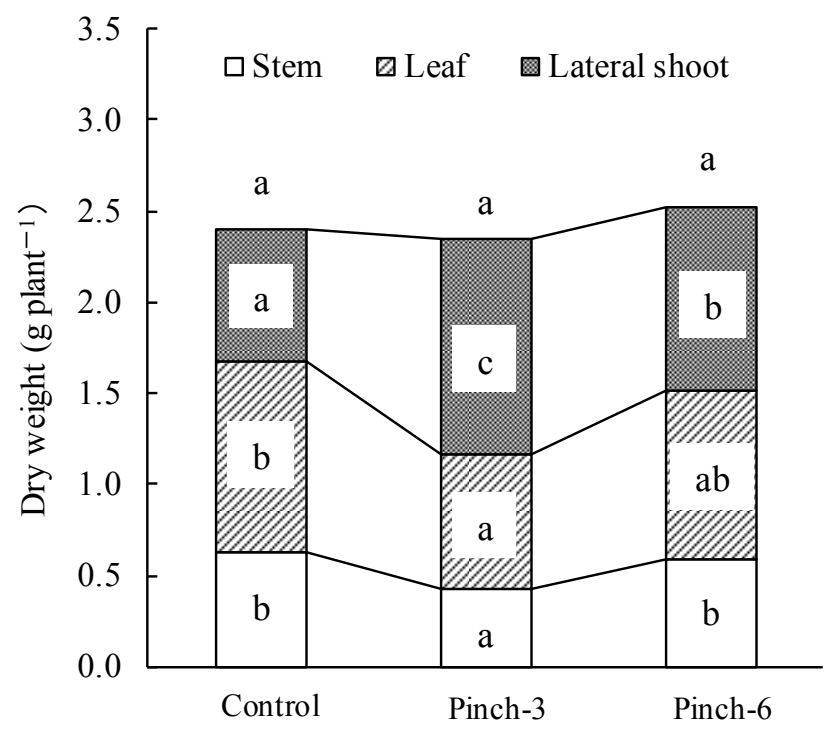

